\title{
Simulation of earthquake-induced hazards of falling exterior non-structural components and its application to emergency shelter design
}

\author{
Zhen $\mathrm{Xu}^{\mathrm{a}}$, Xinzheng Lu${ }^{\mathrm{b}}$, Hong Guanc, Yuan Tian ${ }^{\mathrm{b}}$ and Aizhu Ren ${ }^{\mathrm{b}}$ \\ a School of Civil and Environmental Engineering, University of Science and Technology Beijing, \\ Beijing 100083, P.R. China. \\ ${ }^{\mathrm{b}}$ Key Laboratory of Civil Engineering Safety and Durability of China Education Ministry, \\ Department of Civil Engineering, Tsinghua University, Beijing 100084, P.R. China. \\ ${ }^{\mathrm{c}}$ Griffith School of Engineering, Griffith University Gold Coast Campus, Queensland 4222,
} Australia.

\begin{abstract}
In addition to earthquake-induced structural collapse, hazards related to falling exterior non-structural components of buildings have also been recognized as a significant safety problem. A novel simulation method is proposed herein to reduce such type of hazard, which has rarely been studied in the existing literature. Using a multi-story concentrated-mass shear (MCS) model and specific falling criteria for exterior non-structural components, the hazard ranges of falling objects in a building group are simulated. The uncertainty of ground motion is considered via the incremental dynamic analyses (IDAs). Thus, the distribution probabilities of falling objects during the design life of a building group can be predicted. A residential community area is considered as a case study for calculating the distribution probabilities of falling objects over a design period of 50 years and for selecting a suitable and safe site for an emergency shelter. This study is expected to provide a useful reference for emergency and disaster management.
\end{abstract}

Keywords: Earthquake-induced hazards; Falling objects; Exterior non-structural components; Building group; Emergency shelter.

Correspondence information:

Professor Xinzheng LU

Department of Civil Engineering, Tsinghua University, Beijing 100084, China

Telephone: +86-10-62795364

Email: luxz@tsinghua.edu.cn 
The risk of an earthquake-induced structural collapse of a building has been continuously reduced with advances in research on the collapse resistance of buildings (Villaverde 2007; Lu et al. 2013a; Xu et al. 2013; Li et al. 2014a, 2014b;). During recent earthquakes in several developed countries (e.g., Noto Peninsula in 2007, Christchurch in 2010, and Napa in 2014), the total number of collapsed buildings and the number of deaths and injuries associated with the collapse of buildings were quite small (Hamada et al. 2007; Kaisera et al. 2012; PEER 2014). Conversely, the earthquake-induced hazard produced by falling exterior non-structural components of buildings has become a significant safety problem (Ellidokuz et al. 2005; Johnston et al. 2014). For example, more than fifty percent of injuries incurred during the Northridge earthquake were caused by falling objects (Peek-Asa et al. 1998). Non-structural falling objects also caused a significant number of injuries in the Gujarat, Chi-Chi, and Wenchuan earthquakes (Roy et al. 2002; Chan et al. 2006; Qiu et al. 2010). However, existing research in this area is limited (Braga et al. 2011; Mahdavinejad et al. 2012), potentially resulting in unsafe designs of excavation paths and emergency shelters during and/or after earthquakes. Therefore, further studies are needed to accurately predict the distribution probabilities of the hazard due to falling exterior non-structural components.

An accurate prediction of the distribution probabilities of falling objects can provide an important reference for the selection of safe excavation paths and emergency shelter sites, which can effectively reduce the resulting hazard. Such distribution probabilities can also be used to predict the number of injuries/casualties outside the buildings and to analyze the traversability of roads as a result of falling objects, both of which are critical for pre-earthquake planning and post-earthquake emergency response. To obtain the distribution probabilities of falling objects, three important problems need to be addressed:

Problem (1): The uncertainty of the ground motion. Different ground motions 
with various intensities and time histories significantly influence the dynamic behaviors of buildings, which results in a random distribution of falling objects (Padgett and Desroches 2007; Katsanos et al. 2010).

Problem (2): The complicated dynamic response of a building group. Important factors associated with falling objects include the damage statuses of non-structural components on different stories, and their initial heights and velocities. These factors are significantly influenced by the dynamic response of the buildings. Moreover, the falling objects from different buildings in a building group may overlap each other, making the prediction more challenging because each building in a building group must be accurately simulated.

Problem (3): The falling criteria of exterior non-structural components.

For Problem (1), IDAs based on abundant ground motion records can consider the uncertainty of the ground motion, so that IDA is extensively used for earthquake-induced structural analysis (Mwafy and Elnashai 2001; Antoniou and Pinho 2004; Iervolino et al. 2006; Tothong and Luco 2007; Ferracuti et al. 2009; Shi et al. 2012, 2014). Furthermore, several methods have been proposed for the selection of suitable ground motion records for IDA (Iervolino and Cornell 2005; Azarbakht and Dolšek 2007; Iervolino et al. 2010). For the above reasons, IDAs are appropriate to be used in this study to determine the distribution probabilities of falling objects.

In regard to Problem (2), an efficient numerical model is proposed to accurately simulate the nonlinear dynamic response of each building within a building group. This model will provide necessary data for the hazard analysis of falling non-structural components. Two popular computer software programs, namely, Hazus and MAEviz (McLaren et al. 2008; FEMA 2012), both provide the advanced engineering building module (AEBM) for the seismic damage prediction of a building group. The drawback of the AEBM is its underlying static analysis method (i.e., pushover analysis) for the prediction of damage to buildings, which is unable to provide the initial velocities of falling objects. To predict the nonlinear dynamic response, several high-fidelity structural models have been proposed (e.g., Goulet et al. 2007 and $\mathrm{Lu}$ et al. 2013a). Nonetheless, these models are unsuitable for the present 
study for the following two reasons: (a) A building group typically consists of a large number of buildings, and the use of those high-fidelity models results in an extremely high computational workload. This problem can be exacerbated in IDAs, in which a nonlinear time-history analysis (THA) is repeatedly performed to consider many different ground motions and intensities. (b) The task of obtaining detailed structural data for every building within a building group can be labor intensive, time consuming, and impracticable. Hence, this study attempts to establish an efficient numerical model of a building group based on limited structural information.

Recently, Lu et al. (2014) proposed the MCS model to predict the seismic damage to a building group, and the prediction process can be accelerated by graphics processing unit (GPU)-based parallel computing. This model is capable of efficiently predicting the nonlinear time-history response of each story in numerous buildings within several minutes. In addition, Lu et al. (2014) also proposed a method for determining the essential parameters of the MCS model based on the performance database of Hazus software. Using this method, only five macro-scale variables for the buildings (i.e., structural type, story height, number of stories, construction period and story area) are required to determine these parameters. Given such an advantage, the MCS model is thus adopted in this study to simulate the structural seismic response of a building group.

With respect to Problem (3), rational falling criteria for exterior non-structural components are required to determine whether an object is considered to fall. According to the International Building Code (ICC 2009) and American Society of Civil Engineers (ASCE) standards (ASCE 2010), exterior non-structural wall elements and glazed curtain walls are two commonly used types of exterior non-structural components. Generally, fallings of these components are governed by story drifts. The ultimate drift ratios of curtain walls and exterior non-structural walls have been reported based on laboratory experiments (Sucuoğlu and Vallabhan 1997; Behr 1998; Memari et al. 2003) and specified in design codes (CECS127 2001; JGJ133 2001; JGJ102 2003; ASCE 2010). These ultimate drift ratios can be employed as the falling criteria for these exterior components. By analyzing the falling process, 
the distribution probabilities of the falling objects can then be predicted.

As previously mentioned, the distribution probabilities of exterior non-structural falling objects have numerous possible applications. One of the most important applications is the site selection for emergency shelters. In addition to indoor shelters, such as gymnasiums and large-space public buildings (ARC 2002; FEMA 2008), outdoor shelters (i.e., parks and green spaces) are also extensively utilized (GB50413 2007; GB21734 2008). In many areas with high building densities, temporary outdoor shelters are the only feasible option due to limited space. A critical factor in the design of a temporary outdoor shelter is that it should protect people from falling objects of surrounding buildings. This design principle has been incorporated in the latest design code of China for urban disaster emergency shelters, which is due to be published (CCSN 2014). The code requires that the distance between the shelter and the surrounding buildings should exceed the maximum projected distance of the falling objects. However, the code does not provide a method for calculating the projected distances of the falling objects, which limits the use of the code.

This study aims to propose a novel simulation method for the earthquake-induced hazards of falling exterior non-structural components. The uncertainty of the ground motion is considered using the IDAs. The nonlinear dynamic response of a building group is simulated using the MCS model. The falling criteria and falling behavior of the exterior non-structural components are proposed and simulated. The distribution probabilities of the falling objects are also predicted for the design life of the buildings. A residential community area is selected as a case study, and the distribution probabilities of the falling objects are evaluated over a design period of 50 years. In addition, the hazard region of falling objects is predicted under an acceptable probability, and a reasonable site is selected for an emergency shelter.

\section{Proposed simulation framework}


site selection for emergency shelters is presented in Figure 1. The framework consists of three major components: (C1) calculation of the distribution of falling objects, (C2) uncertainty analysis of the ground motion, and (C3) site selection for emergency shelters.

(C1) Calculation of the distribution of falling objects

The MCS model ( $\mathrm{Lu}$ et al. 2014) is adopted in this study to analyze the nonlinear structural response of a building group under a given ground motion. Specifically, the time-history story drift ratios and velocities are obtained for each story. The resulting story drift ratios and the falling criteria specified in the design standards (ASCE 2010) are subsequently employed to determine the falling statuses of exterior non-structural components. If a component separates from the main structure and falls, it will undergo horizontal projectile motion from its corresponding story with an initial velocity obtained from the nonlinear THA of the building. Subsequently, the projected distances and hazard range of the falling objects from the building under a given ground motion can be determined.

(C2) Uncertainty analysis of the ground motion

The hazard ranges of falling objects subjected to different ground motions and intensities are calculated using the IDAs, from which the fragility curves of the distribution probabilities are obtained. By combining the fragility curves with the seismic hazard of the site, the distribution probabilities of the falling objects over a certain period (e.g., the design life) can be calculated.

(C3) Site selection for emergency shelters

The distribution probabilities of the falling objects of a building group are mapped to the geographic information system (GIS) platform, in which the overlapping regions of the falling objects from different buildings are considered. According to an acceptable probability level, the hazard regions of the falling objects can be determined and a rational site for an emergency shelter can subsequently be selected.

By and large, no similar framework is currently available in the literature for the distribution probabilities of falling objects. Note that the proposed framework 
constitutes three key problems, i.e., the uncertainty analysis, the falling criteria and the structural response analysis of a building group. The first two problems can be performed using the IDA method and the ASCE's standard, respectively. For the third problem, traditionally the Hazus method (FEMA 2012) has been commonly used. However it is not applicable for the analysis of falling objects because only one damage state can be calculated for the whole building. On the other hand, the proposed MCS model, demonstrating several advantages over the Hazus method (detailed in Table 1), is able to determine the damage state for each story.

\section{Simulation method}

A detailed analysis method is presented in this section to elaborate upon the proposed simulation framework.

\subsection{Calculation of the distribution of falling objects}

\section{(C1-1) Structural response analysis}

The structural response analysis of a building group is performed using the previously developed MCS model (Lu et al. 2014). In this model, the mass of a building is assumed to be concentrated at each story, as illustrated in Figure 2. The model is capable of efficiently predicting the time-history data of each story including the story drift, the displacements and the velocities. A previous study (Xu et al. 2014) indicated that the predictions of the MCS model are as accurate as the predictions of a high-fidelity finite element (FE) model when a realistic inter-story hysteretic relationship is adopted. The MCS model was developed particularly for common buildings with regular planar and vertical layouts, as well as given building heights. The Chinese code for seismic design of buildings (GB50011, 2010) specifies the maximum heights for regular buildings. The code specified maximum heights are defined as the height limits in the proposed method. For buildings beyond the maximum heights, special designs and calculations are required. In order to determine the factors of the MCS models, Lu et al. (2014) proposed a method that requires only five macro-scale variables (i.e., structural type, story height, number of stories, 
construction period and story area) to obtain the inter-story hysteretic behavior based on the performance database of Hazus software. Generally, these macro-scale variables can be directly obtained from the GIS database of a city.

After determining the inter-story hysteretic parameters of each building, the nonlinear THA of a building group can be performed to obtain the structural seismic responses.

(C1-2) Determination of falling criteria

According to ASCE design standards (ASCE 2010), the falling of glazed curtain walls and exterior non-structural walls are both controlled by the relative seismic displacement $D_{p}$. Note that their respective allowable displacements differ.

The glass in glazed curtain walls, glazed storefronts and glazed partitions should satisfy the fallout relative displacement requirement of Eq. (1) or $13 \mathrm{~mm}$, whichever is greater.

$$
\Delta_{\text {fallout }} \geq 1.25 I_{e} D_{p}
$$

where $\Delta_{\text {fallout }}$ denotes the relative seismic displacement at which glass fallout from a curtain wall, storefront, or partition occurs; $I_{e}$ represents the importance factor determined in accordance with ASCE 7-10 (ASCE 2010); and $D_{p}$ is the relative seismic displacement that the component must be designed to accommodate.

Similarly, according to ASCE 7-10 (ASCE 2010), the threshold displacement of exterior non-structural walls should not be less than the relative seismic displacement $\left(D_{p}\right)$ or $13 \mathrm{~mm}$, whichever is greater.

As a critical factor of the falling criteria, $D_{p}$ must not be greater than Eq. (2) (ASCE 2010).

$$
D_{p} \leq \frac{\left(h_{x}-h_{y}\right) \Delta_{a}}{h_{s x}}
$$

where $h_{x}$ denotes the height to which the upper connection point of the component is attached; $h_{y}$ denotes the height to which the lower connection point of the component is attached; $h_{s x}$ represents the story height that is used in the definition of the allowable drift; and $\Delta_{a}$ denotes the allowable story drift. 
For glazed curtain walls and exterior non-structural walls, $h_{x}-h_{y}=h_{s x}$; thus, $D_{p}$

$\leq \Delta_{a}$. The allowable story drifts of all types of structures under different risk categories are specified in ASCE 7-10 (ASCE 2010), as summarized in Table 2.

Assuming that $D$ is the story drift on a specific story of a building, based on the worst scenario, an exterior non-structural component begins to fall when $D$ reaches the maximum allowable threshold. Thus, the falling criteria for glazed curtain walls and exterior non-structural walls can be specified by Eq. (3) and Eq. (4), respectively.

$$
\begin{aligned}
& D_{\text {glass }} \geq \max \left(1.25 I_{e} \Delta_{a}, 0.013 \mathrm{~m}\right) \\
& D_{\text {wall }} \geq \max \left(\Delta_{a}, 0.013 \mathrm{~m}\right)
\end{aligned}
$$

Based on Eq. (3) and Eq. (4), the falling statuses of exterior non-structural components can be determined according to the story drifts provided by the nonlinear THA. Generally, the non-structural components are attached and supported by the main structure on each story, instead of the non-structural components of the adjacent stories. As such, the non-structural components of each story are independent from each other. In this study, the effect from the adjacent stories is thus not considered in the falling criteria of the non-structural components.

(C1-3) Calculation of the projected distances

When a non-structural component falls at the $i$-th time step from the $j$-th story, where the height and velocity of the story at the moment of falling are $h_{j}$ and $v_{i, j}$, respectively, the falling objects will undergo a horizontal projectile motion with an initial velocity $v_{i, j}$. Therefore, the horizontal distance from the building at which the falling objects hit the ground can be calculated using Eq. (5).

$$
d_{i, j}=v_{i, j} \sqrt{2 h_{j} / g}
$$

where the velocity $v_{i, j}$ can be obtained from the nonlinear THA using the MCS model.

Eq. (5) indicates that the objects that fall from a higher story will have a higher speed and undergo larger displacement away from the building when they hit the ground. As a result, these falling objects are more hazardous. The hazard range of the falling objects should be determined by the maximum projected distance. If the 
highest story is $m$ and the total number of time steps is $n$, the hazard range of the falling objects can be expressed by Eq. (6):

$$
d_{\max }=\max \left(\left|v_{i, j} \sqrt{2 h_{j} / g}\right|\right), i=1,2,3, \ldots n, j=1,2,3, \ldots m
$$

Due to the uncertainty of the input direction of an earthquake, the hazard range for falling objects in any direction is set to $d_{\max }$. Using this calculation method, the hazard range for falling objects of each building in a building group can be calculated for any given ground motion.

3.2 Uncertainty analysis of the ground motion

Different earthquakes generate ground motions with different frequency components, durations, and amplitudes. The uncertainty of the frequency components and the durations of the ground motions can be simulated using a sufficient number of representative ground motions ( $\mathrm{Lu}$ et al. 2013b, 2013c). Extensive work on ground motion selections has been reported by FEMA P695 (FEMA 2009), in which a typical set of ground motions including far-field and near-field records is recommended. These ground motions were selected based on the following eight principles:

(1) The earthquake magnitude is no less than 6.5 .

(2) The hypocenter is located on the strike-slip fault or the thrust fault.

(3) The records are obtained from soft rock or stiff soil sites, and the shear wave velocity of the site is no less than $180 \mathrm{~m} / \mathrm{s}$.

(4) The far-field records at sites are at least $10 \mathrm{~km}$ from the fault rupture, whereas the near-field records at sites are within $10 \mathrm{~km}$ of the fault rupture.

(5) No more than two of the strongest records are taken from each earthquake.

(6) The strong motion record satisfies peak ground acceleration (PGA) exceeds $0.2 \mathrm{~g}$ and peak ground velocity (PGV) exceeds $15 \mathrm{~cm} / \mathrm{s}$.

(7) The ground motion measuring instruments should be located in a free-field location or on the ground floor of a small building.

(8) The frequency range of the strong motion instrument is at least $4 \mathrm{~s}$.

Thus, by combining the 49 ground motions (22 far-field and 27 near-field records) proposed by FEMA P695 (FEMA 2009) with the widely used El Centro 1940 
EW ground motion record, a set of 50 ground motions is considered in this study to evaluate the uncertainty in the frequency components and the durations of the ground motions.

The uncertainty of the amplitude of a ground motion is simulated using the IDAs. The previously mentioned 50 ground motions are inputted in sequence into the building group by incrementing the intensity measures (IMs).

The probability of the maximum projected distance of the falling objects exceeding $d_{0}$ is defined as $P\left(d_{\max } \geq d_{0}\right)$, where $d_{0}$ is a given distance in the horizontal plane from the perimeter of the building. By conducting the IDAs and a seismic hazard analysis, the total probabilities $P\left(d_{\max } \geq d_{0}\right)$ over the design life of a building group can be obtained. The detailed analysis procedure is elaborated upon in the followings:

(C2-1) IDA of buildings

The number of ground motions employed in the IDA is defined as $N_{\text {total. }}$ In this study, $N_{\text {total }}=50$. These ground motion records are individually assigned to the buildings to perform the corresponding nonlinear THAs. To remain consistent with current seismic design codes, the highly accepted PGA is employed as the IM of the ground motions. If the hazard range $d_{\max }$ of a building, which is derived from the nonlinear THA of a ground motion at a given $I M$ level, exceeds $d_{0}$, this ground motion is recorded as a "dangerous ground motion" at the corresponding IM level. The total number of "dangerous ground motions" among the selected $N_{\text {total }}$ ground motions is defined as $\quad N_{d_{\max } \geq d_{0}}$. Thus, $P\left(d_{\max } \geq d_{0}\right)$ at this $I M$ level can be calculated as follows:

$$
P\left(d_{\max } \geq d_{0} \mid I M\right)=N_{d_{\max } \geq d_{0}} / N_{\text {total }}
$$

By incrementing $I M$ from 0 to $P\left(d_{\max } \geq d_{0}\right)=1.0$, the fragility curve of $P\left(d_{\max } \geq d_{0}\right)$ is obtained. To explain the variation in the probabilities of falling objects under different $I M \mathrm{~s}$, a lognormal distribution function is employed in this study to fit the fragility curve of $P\left(d_{\max } \geq d_{0}\right)$. A numerical example, which is presented in Section 4, reveals that the fitted curve passes the Kolmogorov-Smirnov test at a 5\% significance level. This result confirms that $P\left(d_{\max } \geq d_{0}\right)$ for different $I M$ s follows a lognormal 
distribution.

(C2-2) Seismic hazard analysis

The seismic hazard analysis provides the probability of a specific building site experiencing an earthquake of a given $I M$ during a certain period of time ( $Y$ years), which is denoted as $P(I M)$. Generally, the exceedance probability over a certain design period can be obtained by function fitting method according to the design code and earthquake data for a given site.

(C2-3) Calculation of total probability

Based on the above $P\left(d_{\max } \geq d_{0} \mid I M\right)$ and $P(I M)$, the total probability of $P\left(d_{\max } \geq d_{0}\right)$ over a period of $Y$ years can be calculated using Eq. (8).

$$
P\left(d_{\max } \geq d_{0} \text { in } Y \text { years }\right)=\int_{0}^{+\infty} P\left(d_{\max } \geq d_{0} \mid I M\right) P(I M) \mathrm{d} I M
$$

where $P\left(d_{\max } \geq d_{0}\right.$ in $Y$ years $)$ denotes the total probability of the maximum projected distance of the falling objects exceeding $d_{0}$ in $Y$ years; $P\left(d_{\max } \geq d_{0} \mid I M\right)$ is the conditional probability of $P\left(d_{\max } \geq d_{0}\right)$ for a given $I M$, which is obtained from the fragility curve of $P\left(d_{\max } \geq d_{0}\right)$; and $P(I M)$ represents the probability density that a structure site is hit by an earthquake of a given $I M$ in $Y$ years, which is obtained from a seismic hazard analysis.

The distribution probabilities of falling objects from a building can be obtained by gradually increasing the value of $d_{0}$, which can be used to demonstrate the risk from the hazards of falling objects. In doing so, the risk of these hazards for an entire building group can be obtained, and a suitable and safe site for emergency shelters can then be selected.

\subsection{Site selection for emergency shelters}

A rational prediction of the hazard region of falling objects for a building group is critical for the site selection of emergency shelters. To determine the hazard region, the overlapping of objects that fall from different buildings should be considered. On the GIS platform, the target area in which a building group is located is divided into a number of grids. For each grid, the falling objects from different buildings are assumed to be independent. Therefore, the total probability of the falling objects in a 
grid is equivalent to the sum of the probabilities of individual buildings.

Further, the acceptable probability level of falling hazards should also be determined. An emergency shelter should be located a considerable distance from buildings with a high collapse risk. In ASCE 7-10 (ASCE 2010), the acceptable earthquake-induced collapse risk of a building is $1 \%$ in 50 years. Accordingly, the exceedance probability of $1 \%$ in 50 years is also adopted in this study as the acceptable probability level of falling objects. The risk of falling objects should be less than or equal to the collapse risk of the buildings. Given that the falling objects are important factors to be considered in the site selection of emergency shelters, all grids in the GIS platform in which the probability of falling objects exceeds $1 \%$ over 50 years are considered to form the hazard regions, which are unacceptable for emergency shelter sites.

\section{Case study}

The case study is related to a residential community area. This area encompasses a total of 19 reinforced-concrete buildings with an average of 20 stories and heights of approximately $60 \mathrm{~m}$. According to the Chinese code for seismic design of buildings (GB50011, 2010), the maximum height considered for these residential buildings is $100 \mathrm{~m}$, therefore the buildings having $60.5 \mathrm{~m}$ in height can be simulated by the proposed method. Light hollow brick-infill walls are the primary form of exterior non-structural components of these buildings. Due to limited stiffness of the light walls, their falling does not significantly change the dynamic characteristics of the building. Therefore the impact of non-structural walls to the building's dynamic characteristics is not considered in this study. According to ASCE 7-10 (ASCE 2010), the risk category for these buildings is II and the allowable story drift ratio of the masonry infill walls is 0.020 .

Take a typical 20 -story building with a height of $60.5 \mathrm{~m}$ as an example. The MCS model of this building is created using five variables (i.e., structural type, story height, number of stories, construction period and story area) (Lu et al 2014), and the 
geometric nonlinearity has been considered in this MCS model using Shi et al.'s (2014) method. The seismic responses of this building are simulated using the MCS model, and the fragility curves of $P\left(d_{\max } \geq d_{0}\right)$ for different values of PGAs are calculated. Figure 3 illustrates the fragility curve of the probabilities $P\left(d_{\max } \geq d_{0}\right)$ against different PGAs when $d_{0}$ is equal to $10 \mathrm{~m}$ (i.e., $P\left(d_{\max } \geq 10 \mathrm{~m}\right)$ ), which is fitted by a lognormal distribution (Zareian and Krawinkler 2007). $P\left(d_{\max } \geq 10 \mathrm{~m}\right)$ is nearly zero when the PGA is less than $0.3 \mathrm{~g}$, which implies that the non-structural components will neither fall nor obtain a sufficient velocity to be displaced a distance of $10 \mathrm{~m}$ when PGA is less than $0.3 \mathrm{~g}$. Note that when a PGA of $1.0 \mathrm{~g}$ is attained, $P\left(d_{\max } \geq 10 \mathrm{~m}\right)$ is $100 \%$.

According to the seismic hazard map of the site, the design PGAs with exceedance probabilities of $63 \%, 10 \%$ and $2 \%$ over 50 years are $0.07 \mathrm{~g}, 0.20 \mathrm{~g}$ and $0.41 \mathrm{~g}$, respectively. Adopting the above exceedance probabilities and considering the upper and lower limits of $P($ PGA ) (i.e., $P($ PGA $\geq 0)=100 \%$ and $P(\mathrm{PGA} \geq+\infty)=0 \%$ ), Ma and Xie (2002) proposed Eq. (9) to produce a seismic hazard curve, which is shown in Figure 4.

$$
P(\text { PGA })=1-\exp \left[-\left(\frac{\text { PGA }}{\mathrm{PGA}_{0}}\right)^{-k}\right]
$$

By integrating the fragility curve (Figure 3 ) and the seismic hazard curve (Figure 4), the total probability of $P\left(d_{\max } \geq 10 \mathrm{~m}\right)$ over 50 years can be calculated to be $6.8 \%$. By changing $d_{0}$, the distribution of the total probabilities of falling objects over 50 years, $P\left(d_{0}\right)$, can be obtained, as illustrated in Figure 5. $P\left(d_{0}\right)$ decreases as the projected distance $d_{0}$ increases, which agrees well with real-world observations during earthquakes. In particular, the probability $P\left(d_{0}\right)$ approaches 0 when $d_{0}$ exceeds $15 \mathrm{~m}$, which indicates that the maximum projected distance of falling objects for this building over a period of 50 years will not exceed $15 \mathrm{~m}$.

From the analysis of the distribution probabilities of falling objects for all 19 buildings in the selected community area, the entire distribution probabilities can be obtained, as shown in Figure 6. The red contours denote larger distribution probabilities for falling objects. The overlapping regions of hazard due to falling 
objects from different buildings are considered. As a result, the regions between adjacent buildings are indicated by the darker contours. In terms of the computational cost using a desktop computer (Intel Core2 Q8200, 2.33GHz, 4GB memory), the calculation of the distribution of falling objects takes approximately $10 \mathrm{~s}$ for 19 buildings, under each ground motion and with a specific PGA. However, when considering the uncertainty of different ground motions with different PGAs, the total calculation time is much longer to about $1.4 \mathrm{~h}$.

All hazard regions identified for this community area are shown in Figure 7. The hazard regions encompass a large area of the useable spaces between each building; thus, the available space for emergency shelters is limited. Figure 7 also shows the originally allocated site for the emergency shelter in this community area. Certain portions of the original site overlap with the hazard regions, which is considered to be unsafe and may result in injuries or casualties caused by falling objects. An alternative site location outside the hazard regions is thus selected as a safe area for an emergency shelter. This is also shown in this figure. Note that the total area of the alternative emergency shelter is identical to that of the original shelter, and both are in close proximity to roads and are convenient for evacuation purposes. To this end, the proposed simulation of hazards due to the falling objects has demonstrated a useful application for the site selection of emergency shelters.

\section{Conclusions}

This study proposes a novel simulation method for earthquake-induced hazards caused by falling exterior non-structural components, which has rarely been investigated in the existing literature. The hazard ranges of falling objects in a building group are predicted with a nonlinear THA using the previously developed MCS model. The distribution probabilities of falling objects during the design life of a building is calculated via IDAs and a seismic hazard analysis. A residential community area is selected as a case study to evaluate the distribution probabilities of falling objects, which in turn helps to select a suitable and safe site for an emergency 
shelter. Additional applications of the proposed simulation method, such as the selection of the excavation paths, will be conducted in the future. This study is expected to provide a useful reference for emergency and disaster management. In the future study, the impact of non-structural walls to the building's dynamic characteristics will be further investigated.

\section{Acknowledgements}

The authors are grateful for the financial support received from the National Key Technology R\&D Program (No. 2015BAK14B02), the National Natural Science Foundation of China (No. 51578320, 51308321), and National Non-profit Institute Research Grant of IGP-CEA (Grant No: DQJB14C01).

\section{References:}

American Red Cross (ARC) (2002) Standards for hurricane evacuation shelter selection, ARC 4496. Washington, DC

American Society of Civil Engineers (ASCE) (2010) Minimum design loads for buildings and other structures, ASCE 7-10. Reston, VA

Antoniou S, Pinho R (2004) Advantages and limitations of adaptive and non-adaptive force-based pushover procedures. J Earthq Eng 8:497-522

Azarbakht A, Dolšek M (2007) Prediction of the median IDA curve by employing a limited number of ground motion records. Earthq Eng Struct D 36(15): 2401-2421

Behr RA (1998) Seismic performance of architectural glass in mid-rise curtain wall. Journal of Architectural Engineering-ASCE 4:94-98

Braga F, Manfredi V, Masi A, Salvatori A, Vona M (2011) Performance of non-structural elements in RC buildings during the L'Aquila, 2009 earthquake. Bull Earthq Eng 9:307-324

CECS127 (2001) Technical specification for point supported glass curtain wall. China Association for Engineering Construction Standardization, Beijing (In Chinese)

Chan YF, Alagappan K, Gandhi A, Donovan C, Tewari M, Zaets SB (2006) Disaster management following the Chi-Chi Earthquake in Taiwan. Prehospital and Disaster Medicine 21:196-202

Construction Standardization Information Network (CCSN) (2014) Design code for urban 
disasters emergency shelter (for public comment). http://www.ccsn.gov.cn/ (In Chinese)

Ellidokuz H, Ucku R, Aydin UY, Ellidokuz E (2005) Risk Factors for Death and Injuries in Earthquake: Cross-sectional Study from Afyon, Turkey. Croat Med J 46:613-618

Federal Emergency Management Agency (FEMA) (2008) Design and construction guidance for community safe rooms, FEMA P361. Washington, DC

Federal Emergency Management Agency (FEMA) (2009) Quantification of building seismic performance factors, FEMA P695. Washington DC

Federal Emergency Management Agency (FEMA) (2012) Multi-hazard loss estimation methodology HAZUS-MH 2.1 advanced engineering building module (AEBM) technical and user's manual. Washington, DC

Ferracuti B, Pinho R, Savoia M, Francia R (2009) Verification of displacement-based adaptive pushover through multi-ground motion incremental dynamic analyses. Eng Struct 31:1789-1799

GB21734 (2008) Emergency shelter for earthquake disasters-site and its facilities. Standards Press of China, Beijing (In Chinese)

GB50011 (2010) Code for seismic design of building. China Architecture Industry Press, Beijing (In Chinese)

GB50413 (2007) Standard for urban planning on earthquake resistance and hazardous prevention. China Architecture Industry Press, Beijing (In Chinese)

Goulet CA, Haselton CB, Mitrani-Reiser J, Beck JL, Deierlein GG, Porter KA, et al. (2007) Evaluation of the seismic performance of a code-conforming reinforced-concrete frame building-from seismic hazard to collapse safety and economic losses. Earthq Eng Struct D 36:1973-1997

Hamada M, Aydan O, Sakamoto A (2007) A quick report on Noto Peninsula Earthquake on March 25, 2007, Japan Society of Civil Engineers Report. Tokyo

Iervolino I, Cornell CA (2005) Record selection for nonlinear seismic analysis of structures. Earthq Spectra 21:685-713

Iervolino I, Manfredi G, Cosenza E (2006) Ground motion duration effects on nonlinear seismic response. Earthq Eng Struct D 35:21-38

Iervolino I, Galasso C, Cosenza E (2010) REXEL: computer aided record selection for code-based seismic structural analysis. Bull Earthq Eng 8:339-362

International Code Council (ICC) (2009) International Building Code. Country Club Hills, IL

JGJ102 (2003) Technical code for glass curtain wall engineering. China Architecture Industry Press, Beijing (In Chinese) 
JGJ133 (2001) Technical code for metal and stone curtain walls engineering. China Architecture Industry Press, Beijing (In Chinese)

Johnston D, Standring S, Ronan K, Lindell M, Wilson T, Cousins J, et al. (2014) The 2010/2011 Canterbury earthquakes: context and cause of injury. Nat Hazards 73(2): 627-637

Kaisera A, Holden C, Beavan J, Beetham D, Benites R, Celentano A, et al. (2012) The Mw 6.2 Christchurch earthquake of February 2011: preliminary report. New Zealand Journal of Geology and Geophysics 55(1): 67-90

Katsanos EI, Sextos AG, Manolis GD (2010) Selection of earthquake ground motion records: A state-of-the-art review from a structural engineering perspective. Soil Dyn Earthq Eng 30:157-169

Li Y, Lu XZ, Guan H, Ye LP (2014a) An energy-based assessment on dynamic amplification factor for linear static analysis in progressive collapse design of ductile RC frame structures. Adv Struct Eng 17:1217-1225

Li Y, Lu XZ, Guan H, Ye LP (2014b) Progressive collapse resistance demand of RC frames under catenary mechanism, ACI Structural Journal, 111 (5): 1225-1234

Lu X, Lu XZ, Guan H, Ye LP (2013a) Collapse simulation of reinforced concrete high-rise building induced by extreme earthquakes. Earthq Eng Struct D 42:705-723

Lu X, Lu XZ, Guan H, Ye LP (2013b) Comparison and selection of ground motion intensity measures for seismic design of super high-rise buildings. Adv Struct Eng 16(7): 1249-1262

Lu X, Ye LP, Lu XZ, Li MK, Ma XW (2013c) An improved ground motion intensity measure for super high-rise buildings. Sci China Technol Sc 56(6): 1525-1533

Lu XZ, Han B, Hori M, Xiong C, Xu Z (2014) A coarse-grained parallel approach for seismic damage simulations of urban areas based on refined models and GPU/CPU cooperative computing. Adv Eng Softw 70: 90-103

Ma YH, Xie LL (2002) Determination of frequently occurred and seldom occurred earthquakes in consideration of earthquake environment. Journal of Building Structures 23:43-47 (In Chinese)

Mahdavinejad M, Bemanian M, Abolvardi G, Elhamian SM (2012) Analyzing the state of seismic consideration of architectural non-structural components (ANSCs) in design process (based on IBC). International Journal of Disaster Resilience in the Built Environment 3:133-147

McLaren TM, Myers JD, Lee JS, Tolbert NL, Hampton SD, Navarro CM (2008) MAEviz: an earthquake risk assessment system. In: Proceedings of the 16th ACM SIGSPATIAL International Conference on Advances in Geographic Information Systems, ACM New York, pp 88

Memari AM, Behr RA, Kremer PA (2003) Seismic behavior of curtain walls containing 
insulating glass units. Journal of Architectural Engineering-ASCE 9:70-85

Mwafy AM, Elnashai AS (2001) Static pushover versus dynamic collapse analysis of RC buildings. Eng Struct 23:407-424

Pacific Earthquake Engineering Research Center (PEER) (2014) Preliminary notes and observations on the August 24, 2014, South Napa Earthquake, Report No. 2014/13. University of California, Berkeley

Padgett J, Desroches R (2007) Sensitivity of seismic response and fragility to parameter uncertainty. J Struct Eng-ASCE 133:1710-8

Peek-Asa C, Kraus JF, Bourque LB, Vimalachandra D, Yu J, Abrams J (1998) Fatal and hospitalized injuries resulting from the 1994 Northridge earthquake. Int J Epidemiol 27:459-465

Qiu J, Liu G, Wang S, Zhang X, Zhang L, Li Y, et al. (2010) Analysis of injuries and treatment of 3401 inpatients in 2008 Wenchuan earthquake based on Chinese Trauma Databank. Chinese Journal of Traumatology (English Edition) 13:297-303

Roy N, Shah H, Patel V, Coughlin RR (2002) The Gujarat earthquake (2001) experience in a seismically unprepared area: community hospital medical response. Prehospital and Disaster Medicine 17:186-95

Shi W, Lu XZ, Guan H, Ye LP (2014) Development of seismic collapse capacity spectra and parametric study. Adv Struct Eng 17:1241-1256

Shi W, Lu XZ, Ye LP (2012) Uniform-risk-targeted seismic design for collapse safety of building structures. Sci China Technol Sc 55:1481-1488

Sucuoğlu H, Vallabhan CV (1997) Behaviour of window glass panels during earthquakes. Eng Struct 19:685-694

Tothong P, Luco N (2007) Probabilistic seismic demand analysis using advanced ground motion intensity measures. Earthq Eng Struct D 36:1837-1860

Villaverde R (2007) Methods to assess the seismic collapse capacity of building structures: State of the art. J Struct Eng-ASCE 133:57-66

Xu Z, Lu XZ, Guan H, Han B, Ren AZ (2014) Seismic damage simulation in urban areas based on a high-fidelity structural model and a physics engine. Nat Hazards 71(3):1679-1693

Xu Z, Lu XZ, Guan H, Lu X, Ren AZ (2013) Progressive-collapse simulation and critical region identification of a stone arch bridge. J Perform Constr Fac -ASCE 27 (1): 43-52

Zareian F, Krawinkler H (2007) Assessment of probability of collapse and design for collapse safety. Earthquake Eng Struct Dyn 36(13): 1901-1914 
Figure captions:

Fig. 1 Proposed simulation framework

Fig. 2 The MCS model for a building

Fig. 3 Fragility curve of $P\left(d_{\max } \geq 10 \mathrm{~m}\right)$ against different PGAs

Fig. 4 Seismic hazard curve over 50 years for the site in the case study

Fig. 5 Distribution of total probabilities for falling objects over 50 years

Fig. 6 Distribution probabilities of falling objects in the selected community area

Fig. 7 Hazard regions of falling objects and site location of emergency shelter

Table captions:

Table 1 Comparison between the proposed MCS model and the Hazus method

Table 2 Allowable story drift $\Delta_{a}$ (ASCE 2010) 


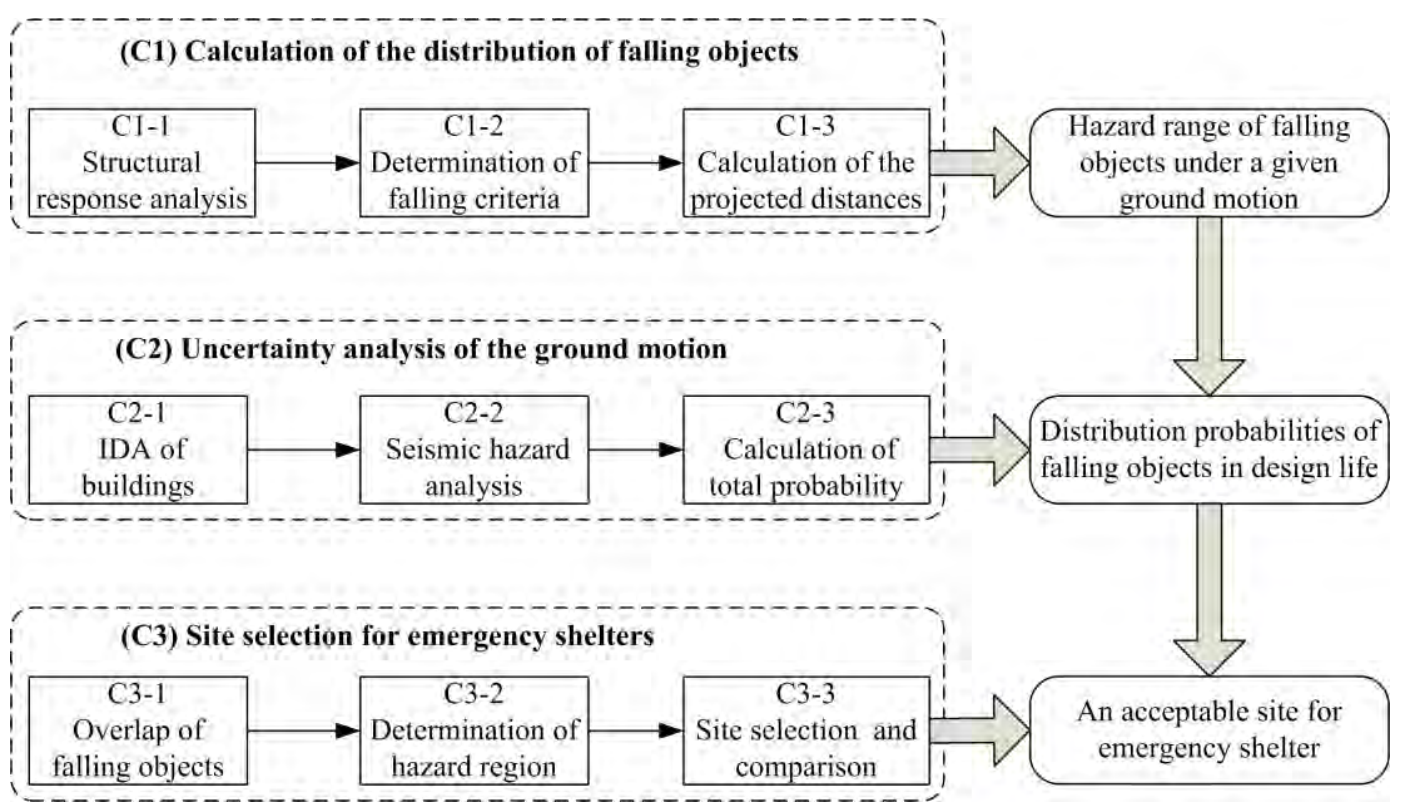

Fig. 1 Proposed simulation framework 

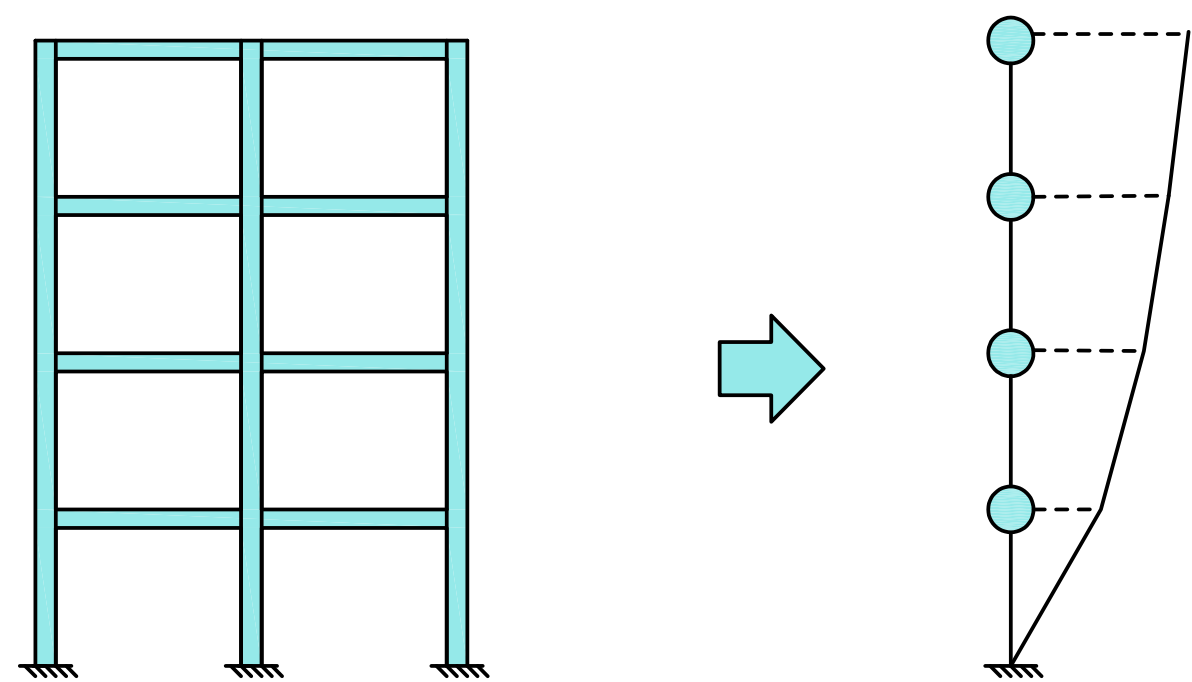

Fig. 2 The MCS model for a building 


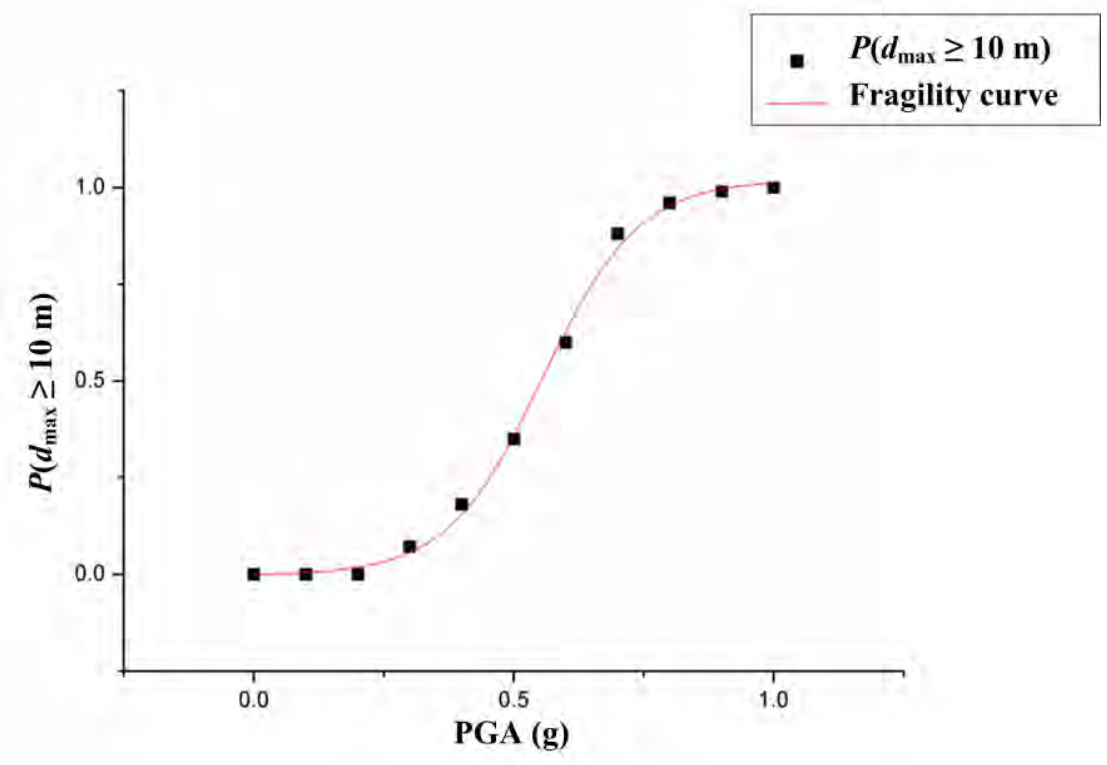

Fig. 3 Fragility curve of $P\left(d_{\max } \geq 10 \mathrm{~m}\right)$ against different PGAs 


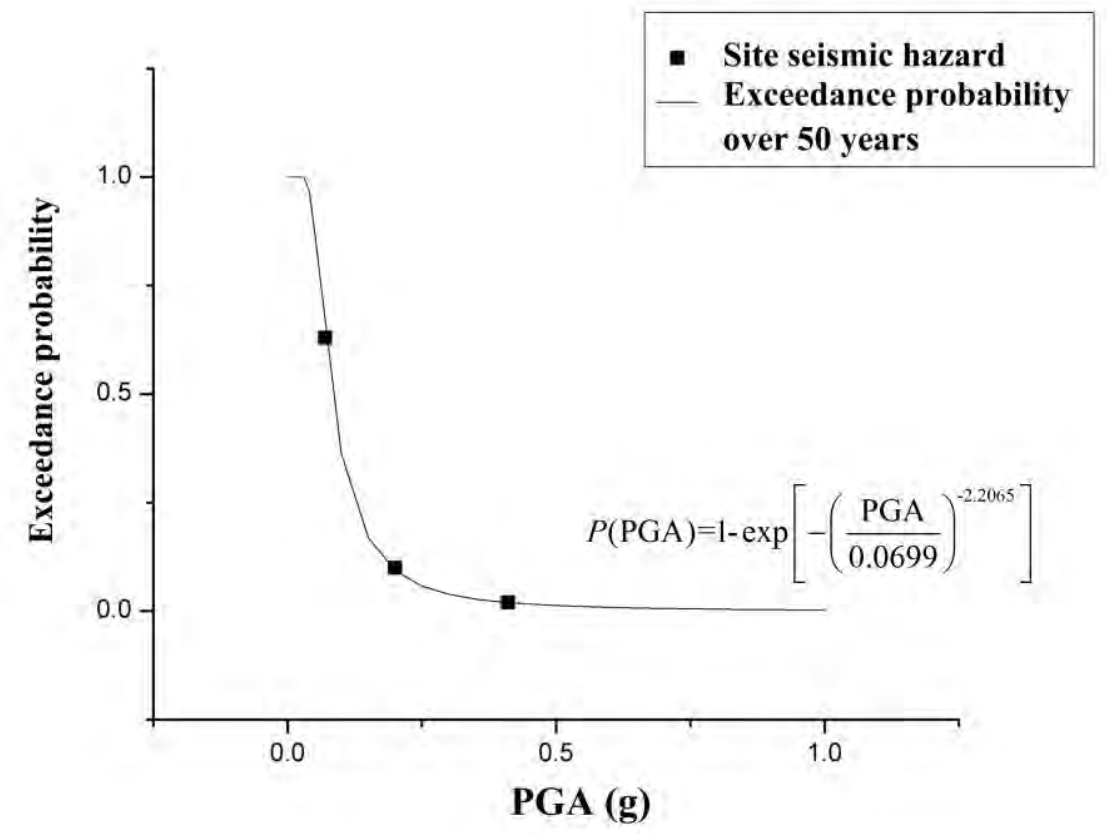

Fig. 4 Seismic hazard curve over 50 years for the site in the case study 


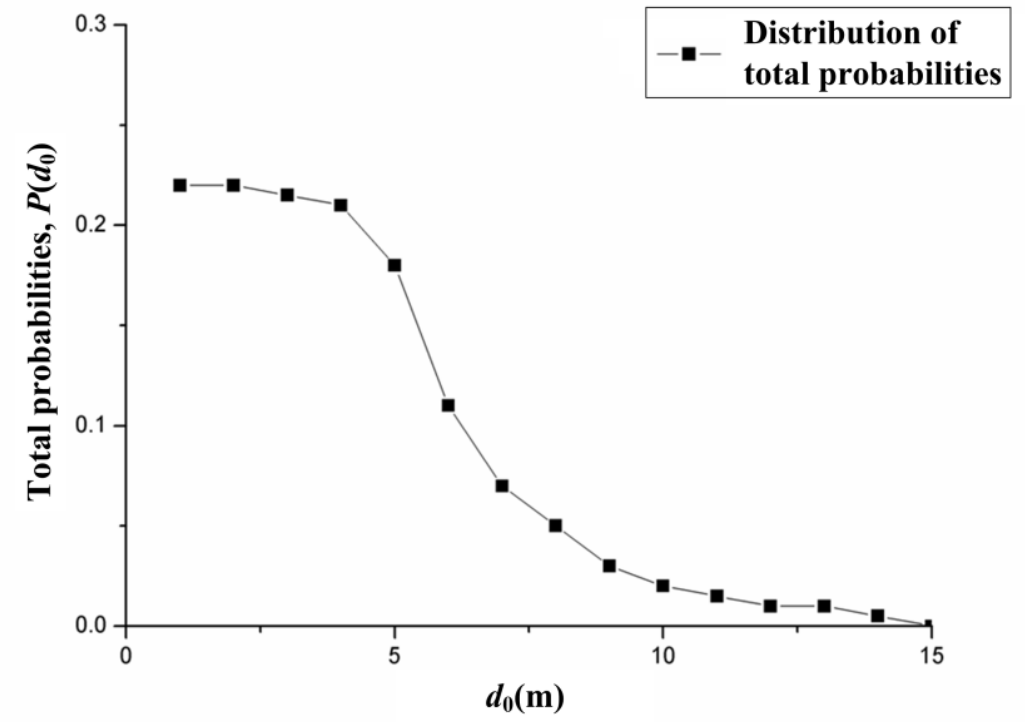

Fig. 5 Distribution of total probabilities for falling objects over 50 years 


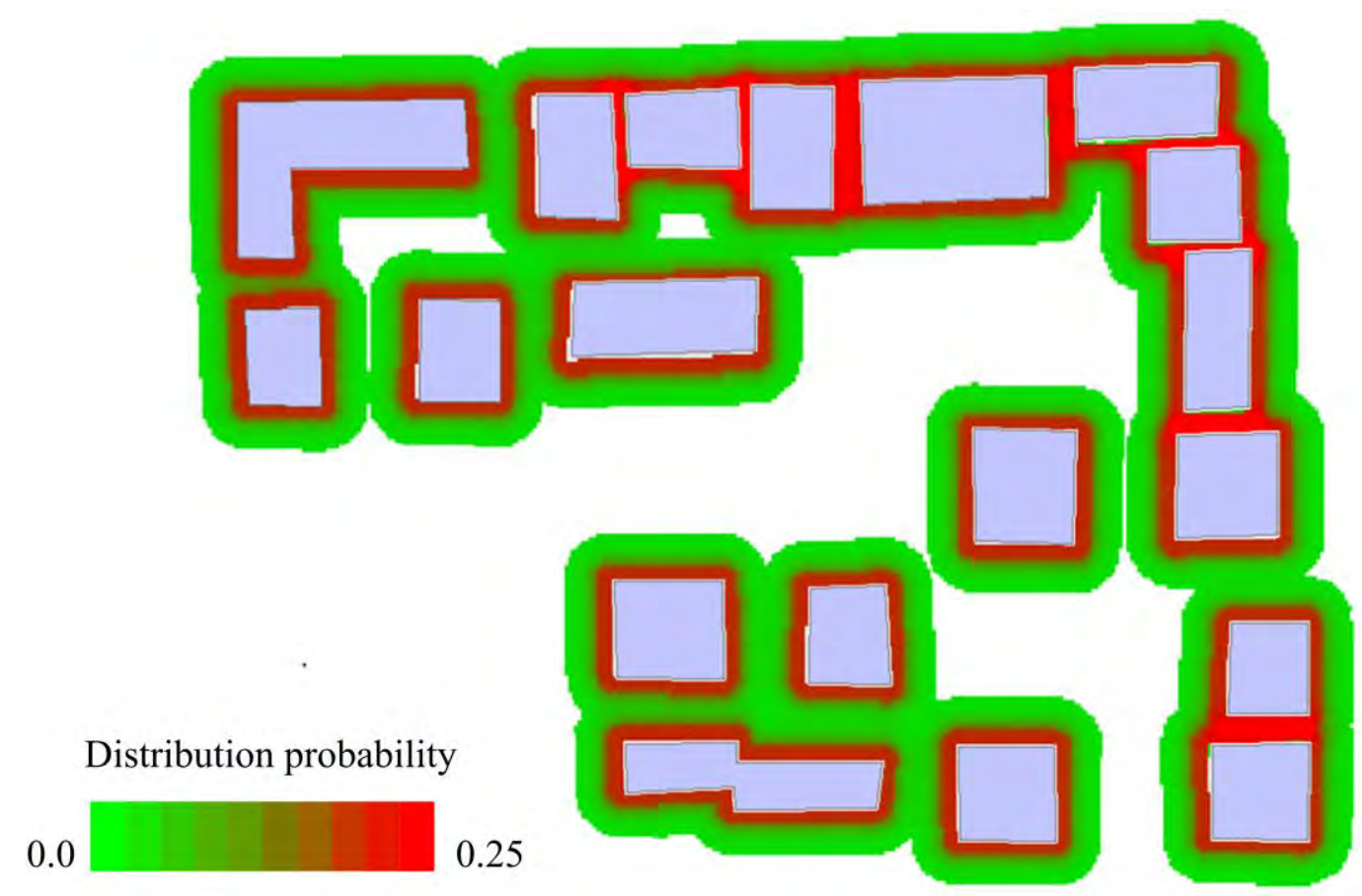

Fig. 6 Distribution probabilities of falling objects in the selected community area 


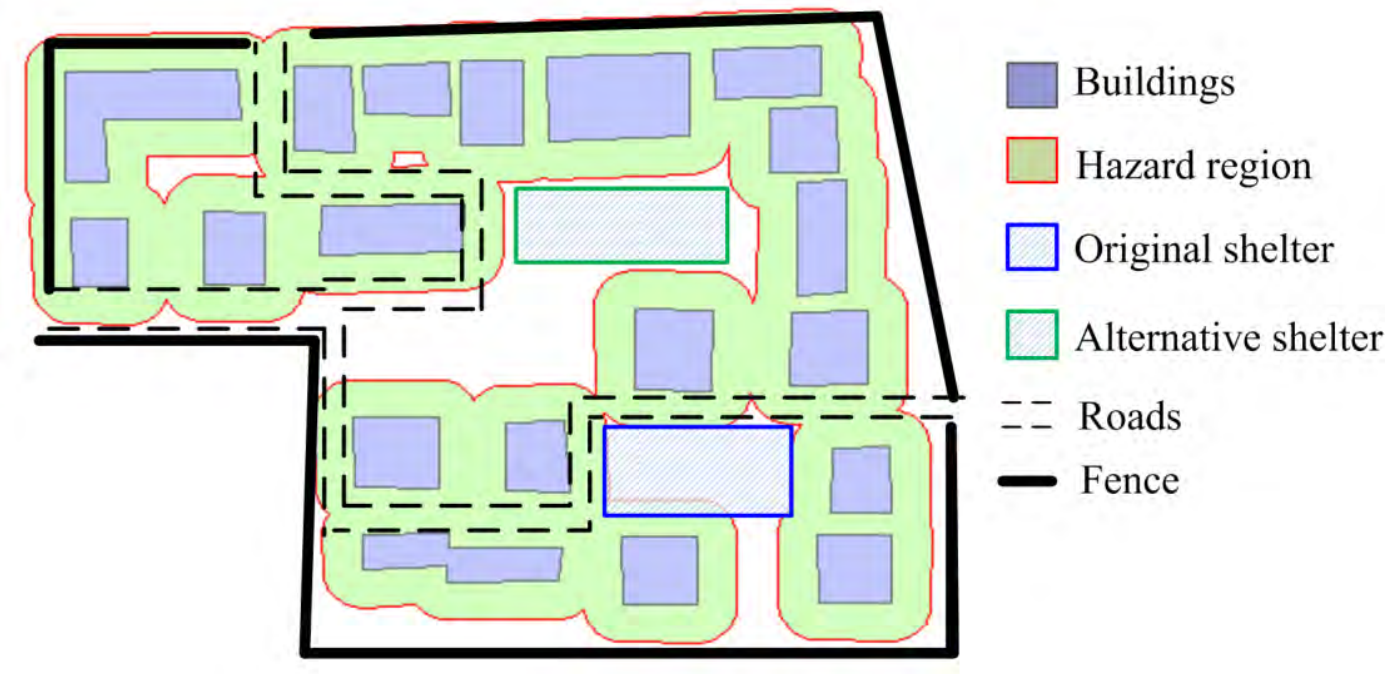

Fig. 7 Hazard regions of falling objects and site location of emergency shelter 
Table 1 Comparison between the proposed MCS model and the Hazus method

\begin{tabular}{|l|c|c|}
\hline \multirow{2}{*}{ Key differences } & \multicolumn{2}{|c|}{ Structural models for a building group } \\
\cline { 2 - 3 } of & The MCS model & The Hazus method \\
\hline $\begin{array}{l}\text { Degree } \\
\text { freedoms (DOFs) }\end{array}$ & Multiple DOFs & Single DOF \\
\hline Analysis method & Time-history analysis & Pushover analysis \\
\hline Damage details & Each story has a damage state & $\begin{array}{c}\text { Each building has only one } \\
\text { damage state }\end{array}$ \\
\hline
\end{tabular}

Table 2 Allowable story drift $\Delta_{a}$ (ASCE 2010)

\begin{tabular}{|l|l|c|c|}
\hline \multicolumn{1}{|c|}{ Structure } & \multicolumn{3}{|c|}{ Risk Category } \\
\cline { 2 - 4 } & I or II & III & IV \\
\hline $\begin{array}{l}\text { Structures, other than masonry shear wall } \\
\text { structures, 4 stories or less above the base, with } \\
\text { interior walls, partitions, ceilings, and exterior } \\
\text { wall systems that have been designed to } \\
\text { accommodate the story drifts. }\end{array}$ & $0.025 h_{s x}$ & $0.020 h_{s x}$ & $0.015 h_{s x}$ \\
\hline Masonry cantilever shear wall structures. & $0.010 h_{s x}$ & $0.010 h_{s x}$ & $0.010 h_{s x}$ \\
\hline Other masonry shear wall structures. & $0.007 h_{s x}$ & $0.007 h_{s x}$ & $0.007 h_{s x}$ \\
\hline All other structures. & $0.020 h_{s x}$ & $0.015 h_{s x}$ & $0.010 h_{s x}$ \\
\hline
\end{tabular}

